\title{
Natal teeth associated with Riga-Fede disease (Sublingual traumatic disease/traumatic lingual ulceration): A case report and review of literature
}

\author{
Lucero Valderrama-Iracheta $^{1 *}$, Karla Eugenia Hernández-Trejo ${ }^{1}$ and Gloria María Rosales-Solis ${ }^{1}$ \\ Department of Pediatrics, School of Medicine and University Hospital “Dr. José Eleuterio González”, Universidad Autonoma de Nuevo Leon (U.A.N.L.), Mexico
}

\begin{abstract}
Introduction: Eosinophilic ulcer of the oral mucosa is a rare, self-limiting condition of unknown origin. Ulceration on the ventral surface of the tongue in newborns or infants is more frequently associated with natal or neonatal teeth.

Case report: This is a 1-month-old male patient with no significant medical history who was brought to our consultation after presenting an ulcer in the ventral region of the tongue, which increased in size and made breastfeeding difficult.

Conclusion: The tooth extraction turned out to be an effective procedure by removing the two incisor neonatal teeth in the lower jaw that the patient had, 2 weeks after extraction the patient evolved favourably without presenting complications.
\end{abstract}

\section{Introduction}

Eosinophilic ulcer of the oral mucosa is a rare, self-limiting condition of unknown origin [1]. The injury was first described by Antonio Riga, an Italian physician in 1881, and additional histological studies and cases were published by F. Fede in 1890, hence it is known as Riga-Fede disease [2,3].

Ulceration on the ventral surface of the tongue in new-borns or infants is more frequently associated with natal or neonatal teeth $[3,4]$, the lesion is usually unifocal, although multifocal lesions and recurrences have been reported [2]. The normal eruption of primary teeth generally begins at 6 months of age [5], the native teeth are teeth present at birth, and "neonatal teeth" are teeth erupted within the first month of life [6].

The lesion begins as an ulcer on the ventral surface of the tongue due to repeated trauma, later progresses to an elongated fibrous mass with the appearance of an ulcerated granuloma and trauma and alterations of the epithelial barrier induced by a toxic virus are implicated in its etiology, with activation of lymphocytes and release of interleukins to then promote the maturation of eosinophils [3].

There may be decreased sucking and feeding due to the mass effect of this lesion and therefore malnutrition, therefore it is necessary to recognize this entity and treat it in time $[3,6]$.

his injury is rare and can easily be mistaken for cancer or a microbial infection. The clinician's knowledge of this entity is important to provide an effective treatment [2]. Treatment should start conservatively and focus on eliminating the source of the trauma. Failure to properly diagnose and treat this injury can lead to dehydration and inadequate nutrient intake with other medical sequelae [4].

\section{Case Report}

This is a 1 -month-old male patient with no significant medical history who was brought to the pediatric outpatient clinic of the Hospital Universitario, "Dr. José Eleuterio González", started his condition 3 weeks prior to coming to our consultation after presenting an ulcer in the ventral region of the tongue, which was increasing in size and made breastfeeding difficult, he was taken to a consultation with a private doctor who indicated unspecified mouthwash without showing improvement.

On physical examination, a normocephalic patient was found, with a $2 \times 2 \mathrm{~cm}$ normal tense anterior fontanel, eyes and conjunctivae without alterations, an appropriately implanted pinna, intact tympanic membrane, an oval ulcer was observed, with raised, edematous edges, well delimited and indurated, with a tendency to bleeding, $2 \times 1 \mathrm{~cm}$ in diameter located on the ventral aspect of the tongue (Figure 1), in addition to two incisive neonatal teeth in the lower jaw, the rest of the physical examination was unchanged. Given the characteristics of the injury and the relationship with the neonatal teeth, the diagnosis of Ulcer from Riga Fede was made. The patient was sent to the pediatric dental office where extraction of neonatal teeth was carried out without complications. Two weeks after the procedure, the patient came to the

${ }^{\star}$ Correspondence to: Lucero Valderrama-Iracheta, Department of Pediatrics, University Hospital "Dr. José Eleuterio González", Universidad Autonoma de Nuevo Leon (U.A.N.L.), Ave. Francisco I. Madero and Ave. Gonzalitos s/n, Col. Mitras Centro, C.P. 64460, Monterrey, Nuevo León, Mexico, E-mail: rodolfot59@ hotmail.com

Key words: eosinophilic ulcer, neonatal teeth, riga fede disease

Received: May 03, 2019; Accepted: May 25, 2020; Published: May 29, 2020 
asymptomatic consultation, adequately tolerating the oral route, with good weight gain.

\section{Discussion}

Periodically, cases describing premature dental eruption have been reported, according to the classification of Massler and Savara (1950) [7], taking as reference the moment of eruption in natal (present at birth) and neonatal teeth (during the first thirty days of lifetime).

It is a rare entity, with a prevalence ranging from 1:2000 to 1:3500 in new-borns, according to some authors, it is observed more frequently in the female gender [6]. The variation in prevalence depends on the population studied. Consistent with the normal deciduous eruption where the lower central incisors are the teeth mainly involved in $85 \%$ of cases.

The etiology of the dental eruption in the natal or neonatal period is unknown, however, Landa et al. consider the probable existence of a genetic etiology. One of the most frequent complications is Riga-Fede ulcer, which consists of ulceration of the ventral surface of the tongue $60 \%$ of the time. It is caused by repeated trauma to the oral mucosa, secondary to protrusion movements and continuous retraction on the teeth. It generally occurs during lactation and by the instinctive process of tongue protrusion $[2,8]$.

The importance of the recognition of this condition is due to its possible relationship with neurological diseases, especially in cases where Riga-Fede injury is late, appearing after 6 months of life [4].

Despite being generally asymptomatic, constant trauma can create enough injury to interfere with diet and affect the nutrition of the patient, as was the case in our patient, therefore, it is necessary to provide timely treatment for these patients and it should start conservatively, oriented to the source of the trauma [6].

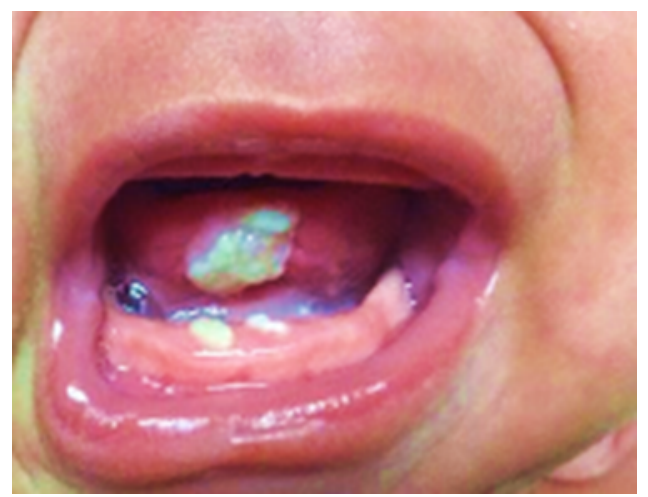

Figure 1. Ulcer in the ventral region of the tongue and lower incisor neonatal teeth

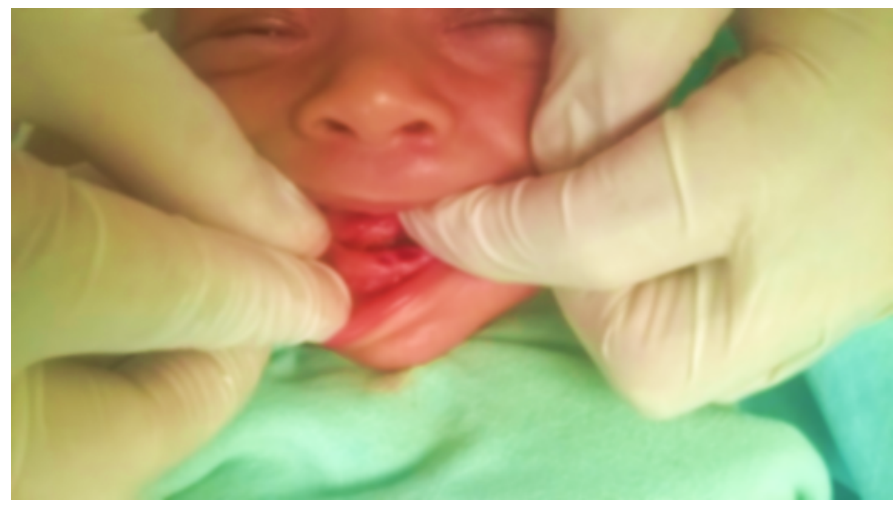

Figure 2. Tooth extraction, performed without complications
Multiple treatments for this pathology have been described, such as filing the teeth or placing acrylic protective covers, in addition to the use of topical corticosteroids to minimize trauma and allow healing of the ulcer [3]. Tooth extraction should be avoided unless the risk of aspiration is high or there are data of dehydration and/or nutritional deficiencies [9], as is our case (Figure 2).

If extraction is the treatment option to follow, the literature review recommends that the procedure be carried out in new-borns older than 10 days of life, due to the risk of bleeding. If the procedure could not be delayed, previous administration of vitamin $\mathrm{K}$ should be considered for greater patient safety [5].

Soft tissue healing after extraction occurs rapidly. However, continuous follow-up is recommended to avoid space alterations and an abnormal trajectory of eruption of permanent teeth, despite the fact that these incidents are rare. Biopsy is required when resolution of the ulcer is not observed during the first two weeks.

\section{Conclusions}

Riga Fede's disease has been little studied in such a way that it is not yet known exactly what its etiology is, as well as there is no fixed treatment for this disease. In the present study, it was observed that tooth extraction turned out to be an effective procedure by removing the two incisor neonatal teeth in the lower jaw that the patient had, 2 weeks after extraction the patient evolved favourably without presenting complications.

The dental extraction procedure must be prepared by an expert, it is recommended that a pediatric dentist do it with a previous assessment of the patient's nutrition as well as verify having a history of applying vitamin $\mathrm{K}$ in order to avoid complications.

\section{References}

1. Mezei MM, Tron VA, Stewart WD, Rivers JK (1995) Eosinophilic ulcer of the oral mucosa. J Am Acad Dermatol 33: 734-740. [Crossref]

2. Joseph BK, Bairava Sundaram D (2010) Oral traumatic granuloma: report of a case and review of literature. Dent Traumatol 26: 94-97. [Crossref]

3. Guzman A, Mendoza G (2005) Dientes natales y enfermedad de Riga-Fede. Dermatol Pediatr Lat 152-157.

4. Choi SC, Park JH, Choi YC, Kim GT (2009) Sublingual traumatic ulceration (a RigaFede disease): report of two cases. Dent Traumatol 25: e48-e50. [Crossref]

5. Khandelwal V, Nayak UA, Nayak PA, Bafna Y (2013) Management of an infant having natal teeth. BMJ Case Rep 2013: bcr2013010049. [Crossref]

6. Mhaske S, Yuwanati MB, Mhaske A, Ragavendra R, Kamath K, et al. (2013) Natal and neonatal teeth: an overview of the literature. ISRN Pediatr 2013: 956269. [Crossref]

7. Massler M, Savara BS (1950) Natal and neonatal teeth: a review of 24 cases reported in the literature. J Pediatr 36: 349-359. [Crossref]

8. Landa RC, Gómez FJ (2018) Dientes natales asociados con enfermedad de Riga-Fede Revista ADM 75: 290-294.

9. van der Meij EH, de Vries TW, Eggink HF, de Visscher JG (2012) Traumatic lingual ulceration in a newborn: Riga-Fede disease. Ital J Pedriatr 38: 20. [Crossref]
Copyright: (C2020 Valderrama-Iracheta L. This is an open-access article distributed under the terms of the Creative Commons Attribution License, which permits unrestricted use, distribution, and reproduction in any medium, provided the original author and source are credited. 